\title{
TTP Curves and Microstructural Evolution Mechanism After Quenching in Aluminum Alloy 6082
}

\author{
Meng Gao $\cdot$ Mengjun Wang $\cdot$ Liu Wen $\cdot$ \\ Guangyao Li
}

Received: 19 April 2012/Revised: 22 June 2012/Published online: 2 October 2012

(C) Springer Science+Business Media New York and ASM International 2012

\begin{abstract}
Temperature-time-property (TTP) curves for aluminum alloy 6082 were acquired by an interrupted quenching method. The TTP curves presented a " $\mathrm{C}$ "-shape and the critical temperature range was $240-440{ }^{\circ} \mathrm{C}$ with temperature at the nose of the $\mathrm{C}$-curve of approximately $335^{\circ} \mathrm{C}$. At this temperature, the greatest rate of second phase development and the largest, and most rapid, drop in hardness was observed. The change was approximately $50 \%$ of the maximum when isothermally held or $50 \mathrm{~s}$. Microstructural evolution of the quenched aluminum alloy 6082 was analyzed with a transmission electron microscope (TEM). TEM analysis results showed that secondary phase particle growth rate was controlled by diffusion. Growth was rapid during the critical temperature range. When the holding time was prolonged, the spherical and needle-shaped precipitates, which provided a significant strengthening effect, rapidly transformed into coarse, rodshaped precipitates. This over-aged condition resulted in loss of the precipitate strengthening effect.
\end{abstract}

Keywords 6082 Aluminum alloy · Hardness ·

Temperature-time-property (TTP) .

Transmission electron microscope (TEM)

M. Gao $(\bowtie) \cdot$ M. Wang $\cdot$ L. Wen

Key Laboratory of Nonferrous Metal Materials Science and Engineering of Ministry of Education, Central South University, Changsha 410083, China

e-mail: lama_csu@126.com

M. Wang · G. Li

Laboratory of Advanced Design and Manufacture for Vehicle Body, Hunan University, Changsha 410082, China

\section{Introduction}

In recent years, with the rapid development of the global shipping industry, an important issue has become a reduction of hull weight to improve the ship's speed. The ship building industry is looking for aluminum alloys that can replace steel components [1-3]. Aluminum alloy 6082 is widely used in the transportation industry and the structural engineering industry for its strength, weldability, corrosion resistance, and light weight. It is also an ideal material for the manufacture of high-performance marine components [4-7].

Alloy 6082 is a heat-treatable alloy that can be precipitation-strengthened to produce the required mechanical properties through solution heat treatment and aging. Theoretically, the higher a material's quenching rate, the greater the material's strength and hardness. However, in practice, a controlled quenching rate can decrease thermal stress and achieve a desirable combination of mechanical properties [8, 9]. Therefore, research is needed in the area of quench sensitivity of this alloy.

Temperature-time-property (TTP) curves are an effective approach to evaluate quench sensitivity and many TTP curves of the aluminum alloys have already been completed to control and improve their response to a rapid quench [10-12]. Fink and Willey [10] examined the quench sensitivity of 7075-T6 alloy using TTP curves, also obtained by an interrupted quenching technique. The information gained was valuable.

In this study, TTP curves of aluminum alloy 6082 were investigated using an interrupted quenching technique. Microstructural evolution during quenching was examined by transmission electron microscopy. The influence of isothermal treatment on the mechanism of microstructural development was revealed. This study aims to provide the basis for the development and optimization of the quenching process. 
Table 1 Chemical composition of aluminum alloy 6082 (wt.\%)

\begin{tabular}{llllllll}
\hline $\mathrm{Mg}$ & $\mathrm{Si}$ & $\mathrm{Cu}$ & $\mathrm{Fe}$ & $\mathrm{Mn}$ & $\mathrm{Zn}$ & $\mathrm{Cr}$ & $\mathrm{Al}$ \\
\hline $0.98-1.10$ & $1.00-1.12$ & 0.10 & 0.50 & $0.52-0.61$ & 0.20 & 0.25 & Bal. \\
\hline
\end{tabular}

\section{Experimental Materials and Method}

The chemical composition of the aluminum alloy 6082 is given in Table 1. Rectangular samples, $20 \times 20 \times 4 \mathrm{~mm}$, were cut along the extrusion direction. Samples were solution heat treated at $530{ }^{\circ} \mathrm{C}$ for $2 \mathrm{~h}$, followed by rapid quenching into a salt bath container set at constant temperatures of 225,350 , and $475{ }^{\circ} \mathrm{C}$. Samples were isothermally held for different times and then water quenched to room temperature. After that, artificial aging was applied at $175^{\circ} \mathrm{C}$ for $6 \mathrm{~h}$. The hardness values were measured using a Brinell hardness tester (HBE-3000 type) with a force of $2450 \mathrm{~N}$ and load dwell time of $30 \mathrm{~s}$.

TEM specimens were prepared from samples first isothermally held for 5, 60, and $450 \mathrm{~s}$ at each of the three temperatures. The samples were mechanically ground to approximately $80 \mu \mathrm{m}$ thickness. Three millimeter diameter discs were then punched out and electropolished by the double-jet method. The electrolyte used was 30\% $\mathrm{HNO}_{3}+70 \% \mathrm{CH}_{3} \mathrm{OH}$, controlled by liquid nitrogen at a temperature below $-20{ }^{\circ} \mathrm{C}$. TEM operating voltage was selected at $220 \mathrm{kV}$.

\section{Results and Discussion}

\section{Isothermal Curves}

The hardness of the samples quenched after the solution treatment was $111.3 \mathrm{HB}$. The hardness of all isothermally aged samples decreased with time. Typical curves are shown in Fig. 1. When isothermal heat treat temperature was high $\left(475{ }^{\circ} \mathrm{C}\right)$, hardness decreased slowly with time; after $10 \mathrm{~min}$, the hardness was approximately $80 \mathrm{HB}$, which was an approximate reduction of $29 \%$. At the moderate temperature of $350{ }^{\circ} \mathrm{C}$, initially hardness decreased sharply and after $80 \mathrm{~s}$ it had dropped by more than $50 \%$ to $55 \mathrm{HB}$. Hardness then remained stable at about $50 \mathrm{HB}$. At $225^{\circ} \mathrm{C}$, the declining rate initially corresponded to the rate observed at $475{ }^{\circ} \mathrm{C}$ and then decreased more slowly. The hardness dropped to $75 \mathrm{HB}$ after $400 \mathrm{~s}$, and remained at this level.

\section{Temperature-Time-Property Curves}

Based on the variation observed for hardness of artificially aged 6082 aluminum alloy at different isothermal

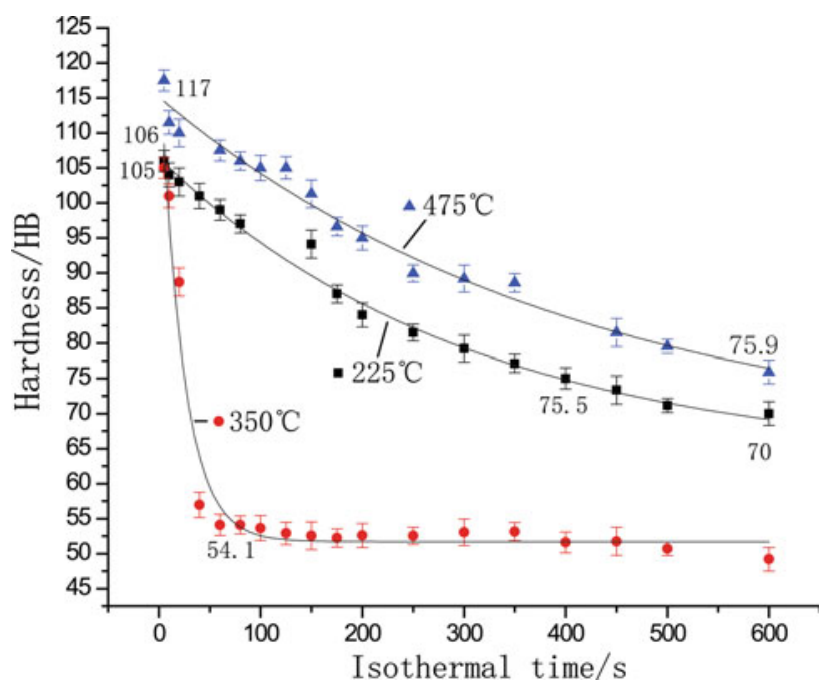

Fig. 1 Hardness-isothermal time curves at different isothermal temperatures for aluminum alloy 6082

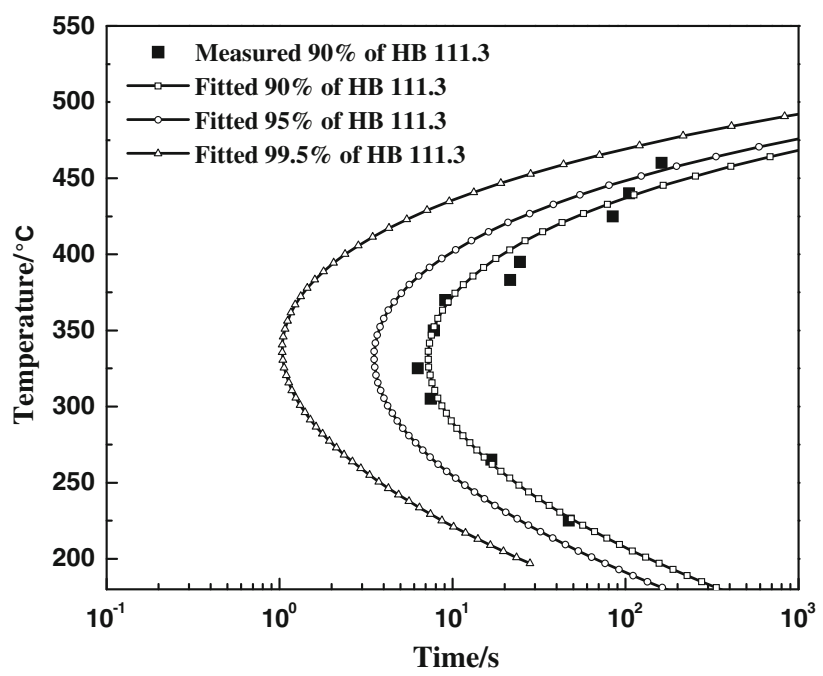

Fig. 2 TTP curves for 6082 aluminum alloy

temperatures, the TTP curves for hardness at 90, 95, 99.5\% of the maximum were constructed as illustrated in Fig. 2. The TTP curves of alloy 6082 are " $\mathrm{C}$ "-shaped, with the nose of the curve at approximately $335^{\circ} \mathrm{C}$. The critical temperature range is $240-440{ }^{\circ} \mathrm{C}$ (based on $99.5 \%$ of maximum hardness curve with a transformation time of $10 \mathrm{~s}$ ).

The equilibrium phase precipitation of alloy 6082 during aging is $\mathrm{Mg}_{2} \mathrm{Si}$. This is a diffusion-controlled phase transformation $[13,14]$. When the supersaturated solid 
solution is quenched at the $10 \mathrm{~s}$ transformation temperature interval, it is easy to precipitate and form the second phase due to a high degree of supersaturation [15].

The phase transformation process changes within the different temperature ranges, thereby affecting the rate of subsequent artificial aging. At the high isothermal temperature range $\left(\geq 440{ }^{\circ} \mathrm{C}\right)$, for the low degree of supercooling and driving force, nucleation rate is low, despite the high solute atom release. Hence, the rate of equilibrium phase precipitation is low, which results in slower changes in hardness value. When the isothermal temperature is low $\left(\leq 240{ }^{\circ} \mathrm{C}\right)$, though the degree of supercooling and driving force are high, the rate of solute atom release remains low because of the low temperature. Therefore, the alloy hardness also decreased slowly with time.

At the moderate temperature interval $\left(240-440{ }^{\circ} \mathrm{C}\right)$, the degree of supercooling and driving force for precipitation are high. In combination with the solute atom release rate, a maximum rate of precipitation and a relatively short incubation period are realized.

\section{The Influence of Isothermal Treatment on Microstructure}

Figure 3 shows TEM microstructures of specimens aged after isothermal aging for 5,60 , and $450 \mathrm{~s}$ at $350{ }^{\circ} \mathrm{C}$. When isothermally held for $5 \mathrm{~s}$, a large number of spherical and a few small needle-shaped precipitates are observed, dispersed in the matrix. When the holding time is extended to $60 \mathrm{~s}$, the dispersed spherical precipitates almost all disappear and are replaced by thin, lath-shaped precipitates, as shown in Fig. 3(b). When the holding time is extended to $450 \mathrm{~s}$, numerous thick, rod-shaped precipitates form with a preferred lattice orientation. Average length of the rods is approximately $1 \mu \mathrm{m}$, as shown in Fig. 3(c). According to the literature [16-18], the precipitation sequence of aluminum alloy 6082 subjected to an isothermal treatment is the same as the aging process.

Both processes can be described as follows:

1. Supersaturated solid solution.

2. Spherical-shaped coherent Guinier-Preston (GP) zones.
Fig. 3 Typical TEM images of precipitate morphology and density present in aluminum alloy 6082 samples after isothermal treatment at $350{ }^{\circ} \mathrm{C}$ for different times. a $5 \mathrm{~s}$, b $60 \mathrm{~s}$, c $450 \mathrm{~s}$

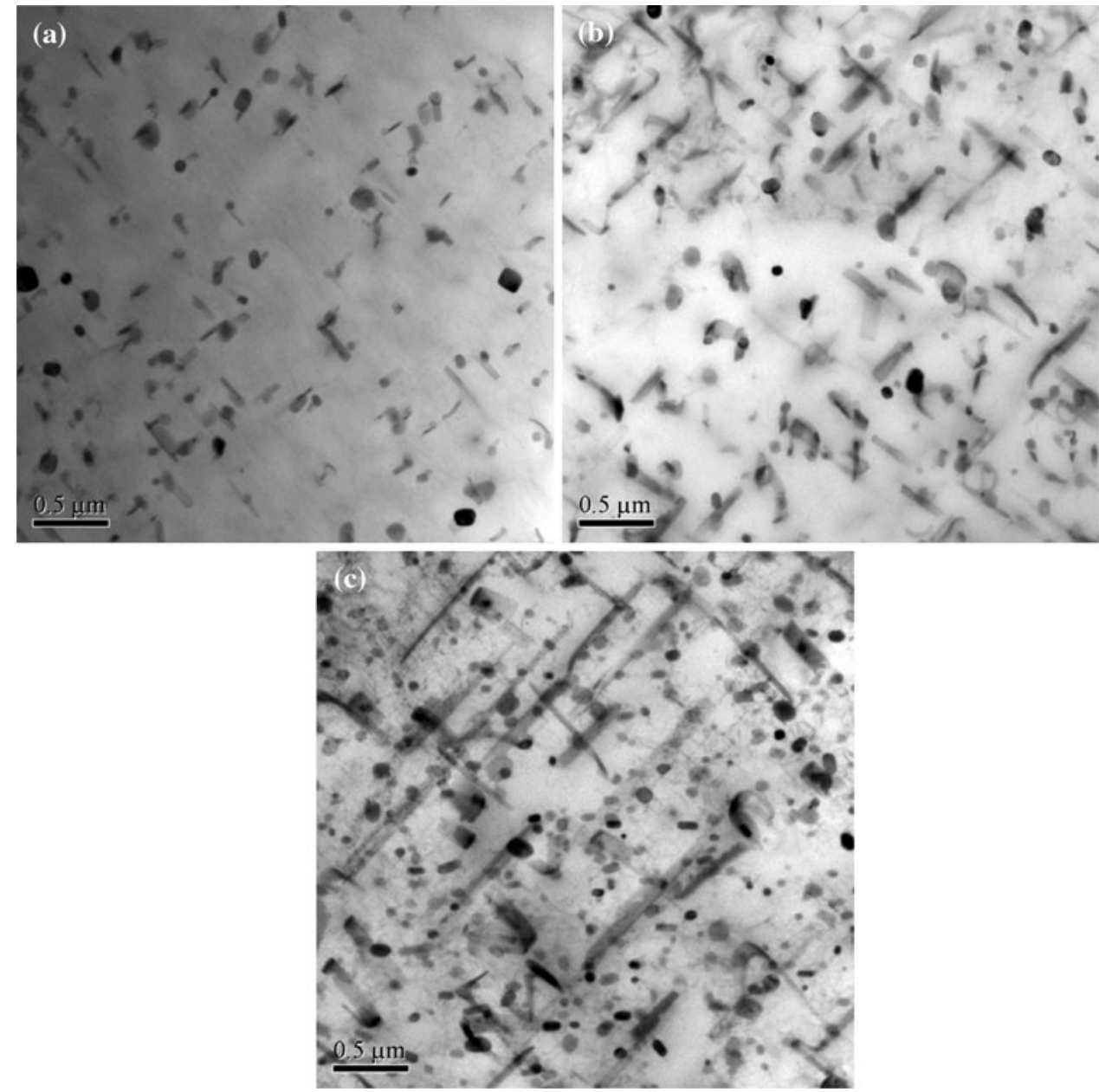


3. Needle-shaped $\beta^{\prime \prime}$ metastable phase.

4. Rod-shaped $\beta^{\prime}$ metastable phase.

5. Incoherent $\beta$ equilibrium phase.

It is possible to conclude from Fig. 3(a) that the spherical precipitates are GP zones, and the small needle-shaped precipitates are the $\beta^{\prime \prime}$ metastable phase. With extended time, Fig. 3(b), the thin, lath-shaped precipitates should develop into needle-shaped $\beta^{\prime \prime}$ metastable phase and the rod-shaped $\beta^{\prime}$ metastable phase. In Fig. 3(c), the thick rodshaped precipitates are the $\beta$ equilibrium phase, together with a small amount of $\beta^{\prime}$ metastable phase.

Based on the TTP curves, when the hold time is $<5 \mathrm{~s}$, there should be no precipitates. This short exposure is still in the incubation period (cluster formation), and the equilibrium precipitation process has not initiated. The precipitates have not had enough time to grow. The size of the precipitate nuclei is small within the supersaturated solid solution. There is a high solute atom and vacancy concentration after quenching, and GP zones, followed by $\beta^{\prime \prime}$ phase, will eventually nucleate.
Due to the high density of GP zones and partially coherent $\beta^{\prime \prime}$ phase in the matrix, there is a strong resistance to dislocation movement, leading to high hardness value $(\mathrm{HB}=102)$. After an isothermal hold for $60 \mathrm{~s}$ at $350{ }^{\circ} \mathrm{C}$, spherical GP zones largely disappear, and are replaced by needle-shaped $\beta^{\prime \prime}$ and rod-shaped $\beta^{\prime}$ phase. During the aging process, these phases develop and grow by assimilation of solute atoms. Although both phases are partially coherent, the needle-shaped $\beta^{\prime \prime}$ phase is better than the $\beta^{\prime}$ phase for a strengthening effect [19].

After aging for $450 \mathrm{~s}$ at $350{ }^{\circ} \mathrm{C}$, some thin, rod-shaped $\beta^{\prime}$ phase and a large number of the $\beta$ equilibrium phase were observed. At this stage, strengthening effect was low. With solute concentration now reduced to a low level, hardness of the alloy was significantly reduced. This is consistent with the experimental results.

When aluminum alloy 6082 is isothermally heat treated within the quench-sensitive range, the spherical and needleshaped precipitates that have a significant strengthening effect are rapidly transformed into coarse, rod-shaped precipitates as isothermal hold-time increases. The result is a
Fig. 4 Typical TEM images at different temperatures for the same isothermal aging time, aluminum alloy 6082. a $225^{\circ} \mathrm{C}$, b $350{ }^{\circ} \mathrm{C}$, c $475{ }^{\circ} \mathrm{C}$

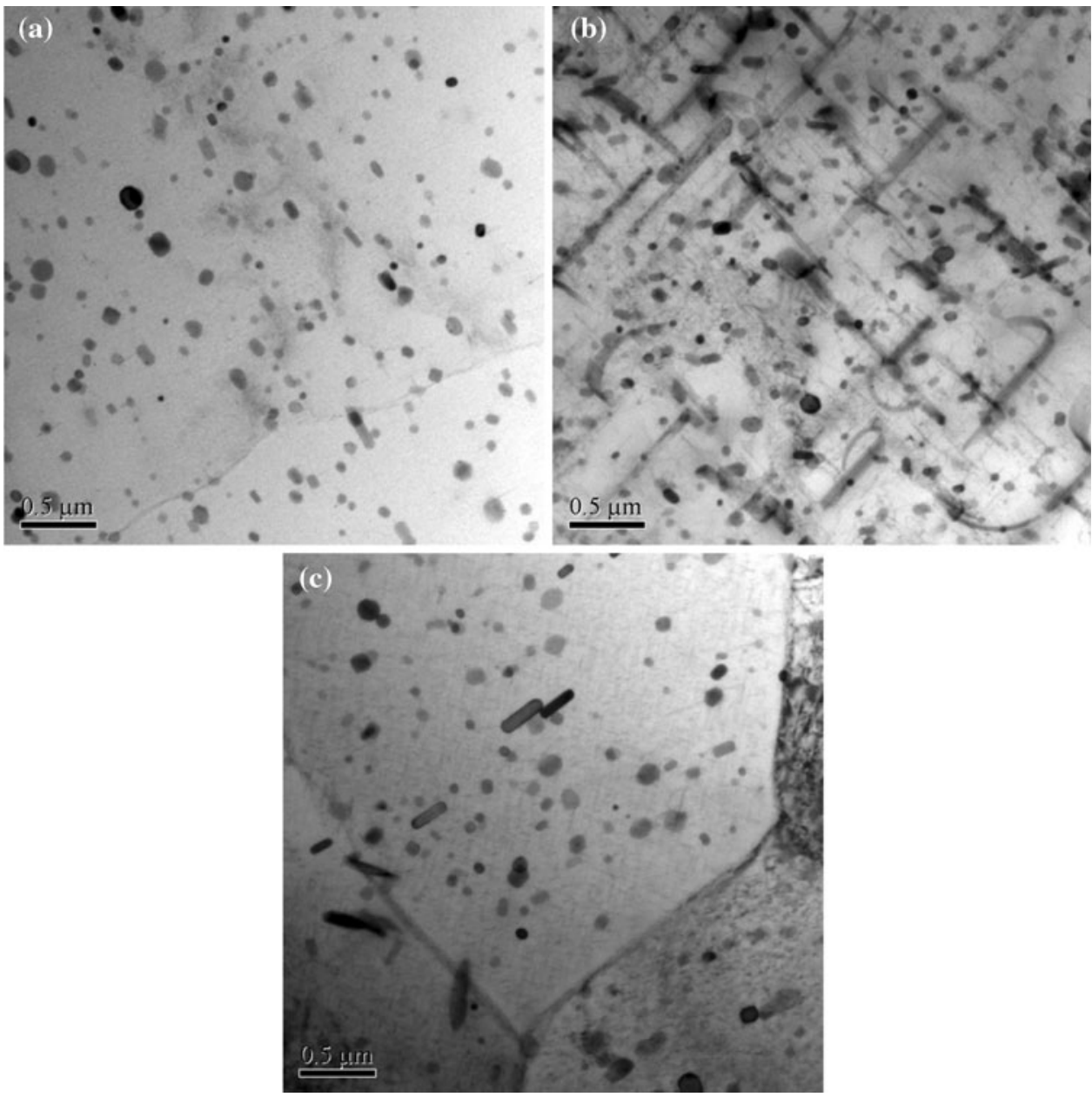


decrease in degree of alloy saturation and a reduction of the precipitate strengthening effect. Figure 4 shows the TEM microstructure of aged specimens after isothermal treatment at different temperatures $\left(225,350\right.$, and $\left.475{ }^{\circ} \mathrm{C}\right)$ for $450 \mathrm{~s}$. When isothermally treated at 225 and $475{ }^{\circ} \mathrm{C}$, a larger number of spherical precipitates and some needle-shaped precipitates form and are dispersed in the matrix. At $225{ }^{\circ} \mathrm{C}$, with a higher temperature gradient, the driving force is high, so the alloy nucleation rate is higher, while the diffusion rate is slow. The result is a slow precipitation rate.

At $475{ }^{\circ} \mathrm{C}$, although the temperature is high, providing a faster diffusion rate the phase transition driving force is low because of the low temperature gradient. The result is also a slow nucleation rate.

TTP curves at 225 and $475{ }^{\circ} \mathrm{C}$ show little precipitation in the matrix. In the subsequent artificial aging process, the supersaturated solid solution forms spherical GP zones and the needle-shaped $\beta^{\prime \prime}$ metastable phase. Figure 4(a) and (c) shows the associated lattice deformation, which results in a strengthening effect and a high hardness value.

Hardness decreases slowly with the holding time and when treated at $350{ }^{\circ} \mathrm{C}$, Fig. 4(c), a large number of thick, lath-shaped precipitates appear in the matrix. These are mostly the $\beta$ equilibrium phase, but some $\beta^{\prime}$ metastable phase is still present. At this temperature, nucleation rate is high and the diffusion rate is relatively fast so the rate of precipitation is at a maximum. As a result, spherical GP zones and needle-shaped $\beta^{\prime \prime}$ metastable phase transform quickly into rod-shaped $\beta^{\prime}$ metastable phase and $\beta$ equilibrium phase. The $\beta$ phase is incoherent and therefore generates minimal lattice strain. Its formation, therefore, results in a poor strengthening effect.

\section{Conclusions}

1. The hardness variation of aluminum alloy 6082 can be divided into three regions: When the samples are isothermally heat treated at high temperature $\left(\geq 440{ }^{\circ} \mathrm{C}\right)$, hardness of the alloy decreases slowly with aging time. At moderate temperature intervals $\left(240-440{ }^{\circ} \mathrm{C}\right)$, hardness decreases sharply. At lower temperatures $\left(\leq 240{ }^{\circ} \mathrm{C}\right)$, the hardness decreases slowly.

2. The nose temperature of the TTP curves for aluminum alloy 6082 is about $335^{\circ} \mathrm{C}$, and the critical temperature ranges from 240 to $440{ }^{\circ} \mathrm{C}$.

3. When isothermally treated at about $350{ }^{\circ} \mathrm{C}$, the second phase precipitates at the fastest rate. As the holding time increases, the spherical and needle-shaped partially coherent precipitates quickly transform into coarse rod-shaped incoherent precipitates, thereby leading to a decrease of solute saturation and reduction in the precipitate strengthening effect.
Acknowledgments This work was funded by the Major Science and Technology Project of Guangdong Province, China (2009A080205003) and the Foundation of State Key Laboratory of Advanced Design and Manufacture for Vehicle Body (31115029).

\section{References}

1. D.J. Eyres, F.R.I.N.A.,6-aluminium alloy, Ship Construction, 6th edn. 2007, p. 50-54

2. S.J. Kim, S.K. Jang, A slow strain rate test experiment to evaluate the characteristics of high-strength $\mathrm{Al}-\mathrm{Mg}$ Alloy for application in ships. Mater. Sci. Forum 510-511, 162-165 (2006)

3. S.P. Woong, S.C. Min, S.H. Myung, H.K. Myung, M.L. Jae, Comparative study on mechanical behavior of low temperature application materials for ships and offshore structures: part Iexperimental investigations. Mater. Sci. Eng. A 18, 5790-5803 (2011)

4. J. Davis (ed.), Corrosion of Aluminum and Aluminum Alloys (ASM International, Materials Park, 1999), pp. 25-49

5. S. Dadbakhsh, T.A. Karimi, C.W. Smith, Strengthening study on $6082 \mathrm{Al}$ alloy after combination of aging treatment and ECAP process. Mater. Sci. Eng. A 527(18-19), 4758-4766 (2010)

6. E. Hollingsworth, H. Hunsicker, Metals Handbook, vol. 13, 9th edn. (ASM International, Materials Park, 1987), pp. 583-609

7. J. Hatch (ed.), Aluminum Properties and Physical Metallurgy (ASM International, Materials Park, 1984), pp. 58-319

8. J.S. Robinson, R.L. Cudd, D.A. Tanner, G.P. Dolan, Quench sensitivity and tensile property inhomogeneity in 7010 forgings. Mater. Process. Technol. 119, 261-267 (2001)

9. V.G. Davydov, L.B. Ber, TTT and TTP aging diagrams of commercial aluminium alloys and their use for aging acceleration and properties improvement. Mater. Sci. Forum 396-402, 1169-1174 (2002)

10. W.L. Fink, L.A. Willey, Quenching of $75 \mathrm{~S}$ aluminum alloy. Trans. AIME 175, 414-427 (1948)

11. G.P. Dolan, R.J. Flynn, D.A. Tanner, Quench factor analysis of aluminum alloys using the Jominy end quench technique. Mater. Sci. Technol. 21, 687-692 (2005)

12. V.G. Davydov, L.B. Ber, E.Y.A. Kaputkin, V.I. Komov, O.G. Ukolova, E.A. Lukina, TTP and TTT diagrams for quench sensitivity and aging of 1424 alloy. Mater. Sci. Eng., A 280, 76-82 (2000)

13. S.J. Andersen, H.W. Zandbergen, J. Jansen, C. Traeholt, U. Tundal, O. Reiso, The crystal structure of the $\beta^{\prime \prime}$ phase in Al-Mg-Si alloys. Acta Mater. 46(9), 3283-3298 (1998)

14. J.W. Evancho, J.T. Stately, Kinetics of precipitation in aluminum alloys during continuous cooling. Metall. Trans. 5, 43-47 (1974)

15. D.A. Porter, K.E. Easterling, Phase Transformations in Metals and Alloys[M], 2nd edn. (Chapman \& Hall, London, 1922), pp. $185-260$

16. S.K. Panigrahi, R. Jayaganthan, V.A. Pancholi, DSC study on the precipitation kinetics of cryorolled Al 6063 alloy. Mater. Chem. Phys. 122(1), 188-193 (2010)

17. Y.S. Sato, H. Kokawa, M. Enomoto, Microstructural evolution of 6063 aluminum during friction-stir welding. Metall. Mater. Trans. A 30(9), 2429-2437 (1999)

18. R.G. Gupta, P.H. Maoris, D.J. Lloyd, Study of the precipitation kinetics in a 6000 series automotive sheet material. Mater. Sci. Forum 217-222, 801-808 (1996)

19. C.D. Marioara, S.J. Andersen, J. Jansen, H.W. Zandbergen, The influence of temperature and storage time at RT on nucleation of the $\beta$ " 'phase in a $6082 \mathrm{Al}-\mathrm{Mg}-\mathrm{Si}$ alloy. Acta Mater. 51, 789-796 (2003) 